\title{
Correction to: Molecular Biodiversity Convergence with Biogeography and Ethnobotany of Rare and Endangered Medicinal Plants from Northern Vietnam
}

N. V. Huy, H. V. Hung, R. T. Buckney, and L. F. De Filippis

\section{Correction to:}

Chapter 1 in: M. Ozturk, K. R. Hakeem (eds.),

Plant and Human Health, Volume 1, https://doi.org/10.1007/978-3-319-93997-1_1

The name of one of the chapter authors of chapter 1 was inadvertently listed as H. V. Huy. This has now been amended throughout the book correctly as N. V. Huy.

The updated online version of this chapter can be found at https://doi.org/10.1007/978-3-319-93997-1_1 